\title{
Observed and Simulated Changes in Precipitation over Sahel Region of West Africa
}

\author{
Agumagu $\mathbf{O}^{\star}$ \\ Department of Geography, University of Sussex, UK \\ *Corresponding author: Agumagu O, Department of Geography, University of Sussex, UK, Tel: +44 1273 877238; E-mail:obroma4u@yahoo.com \\ Received date: Apr 07, 2016; Accepted date: Apr 23, 2016; Published date: Apr 28, 2016
}

Copyright: @ 2016 Agumagu O. This is an open-access article distributed under the terms of the Creative Commons Attribution License, which permits unrestricted use, distribution, and reproduction in any medium, provided the original author and source are credited.

\begin{abstract}
There is an increasing need for strategic evaluations of changes in precipitation in current and future conditions. The paper simulates West African Sahel region climatology, describing the major characteristic of precipitation variability and trends in the region. The study assess the changes in precipitation in Sahel region using observational data output from Global Precipitation Climate Centre (GPCC) and Climate Research Unit (CRU) data set together with General Climate Model (GCM) AR4 used by Intergovernmental Panel on Climate Change (IPCC) to investigate precipitation trends over the Sahel region. In West Africa, rainfall has been subject to large decadal and inters decadal variation. A period of $(1910-2009,2050-2080)$ was chosen to understand the climatic variability across the Sahel region. Mike Hulme in his paper described Sahel climate as the most dramatic example of climatic variability that the world has observed. It is consequently significance to understand if, and to which extent climate trends in the Sahel region exist that influence availability of water in future.

The study demonstrates that the characteristics of rainfall variability in Sahel region differ markedly. The analyses show that the Northern part of the Sahel region is characterizes by low precipitation while the West Coast and Gulf of Guinea rainfall are apparent, although uncertainty from the GCM cannot be over role. The rationale behind the study is the need to understand the nature of climate change in the region over the past 100 years in relation to changes in precipitation together with the spatial pattern of these changes.
\end{abstract}

Keywords: Sahel region; Precipitation; Climate change; Weather hazards

\section{Introduction}

Changes in the climate and climate variability have become important topics raised by relevant scientific communities, most especially climatological branches that assess the influence of climate change. Recent developments in understanding, the influence of climate change in food production, water resource planning and ecosystems, especially in regions with scarce freshwater resources, have brought seasonal-to-inter annual climate predictions into everyday life. The effect of variability on precipitation is of great concern specifically across Africa where rainfall plays an essential role in sustaining livelihoods and economic development. Changes in precipitation are very significant, it is one of the weather elements whose future changes will have a large impact on African nations whose natural resources are dependent on rainfall [1]. A decrease in mean precipitation would lead to increased risk of drought while an increase in mean precipitation would lead to increased risk of flooding. Recent years have seen a number of weather events cause large losses of life as well as a tremendous increase in economic losses from weather hazards.

Sahel region of West Africa has been recognized as an area of global environmental change, but understanding of climatic and anthropogenic-forcing driving the change is not sufficient [2]. The region source of livelihood is dependent on rain-fed agriculture and very strong drought (in the 1970s and 1980s) was a great loss of agricultural production and livestock; loss of human lives to hunger, undernourishment and diseases; displacement of people and devastated economies [3]. The drought incidence really attracted scientific attention to investigate the mechanism responsible for the occurrence [4]. Many researchers have tried to link the drought to tropical factor such as ENSO, Sea Surface Temperature (SSTs) and Inter Tropical Convergence Zone [5]. Despite the controversy regarding the albedo change Xue and Shukla [6] argue that desertification has been occurring in Africa, which may have led to Sahel drought.

Drought is said to occur when a region receives consistent below average precipitation. However Sahel droughts seem to occur a little more frequently due to reduced rainfall. Batterbury and Warren [7] described the short and long-term effects of drought as greatest in the region that is poor, as indeed was much of the Sahel region in the early 1970 s and 1980s. Because of the severity of Sahel drought it was estimated that in 1972 and 1982 about 100,000 people in Sahel region died from hunger and in 1974 about 75,000 were depending on food aid [8].

Although many studies have examined the aspects of Sahel region precipitation trends, the model forecasts a decrease of annual rainfall over Sahel in future [9]. Nevertheless, the degrees to which this variability can be termed natural as opposed to anthropogenic remain uncertain. Thus, there has not been a robust finding in the literature and many opinions reflect decrease in precipitation tends [10]. Liebmann et al. [11] argue that understanding the possible effect of climate variability in Sahel region precipitation is difficult because, Africa as a whole has not been studies in a clearly noticeable manner. The future occurrence of Sahel region droughts and the development of its hydrological balance are therefore of great concern. 
Observational records are crucial for identifying changes in rainfal patterns. GCM are valuable tools for understanding the physical mechanisms driving past, current and future climate variability and changes through the use of climate change scenarios. And provide the only physically based approach accessible to predict future changes in the climate. These portray the important of GCM in assessing the precipitation change. Despite the progress attained in the last few years in using GCM to estimate the influence of the changing climate on water resource, there are still many unsolved problems. An uncertainty has often been a limiting factor. The paper examine Sahel region of West Africa precipitation variability and trends as portrayed by an range of observational data sets output from GPCC and CRU together with GCM AR4 used by IPCC to characterize and understand vigorous changes in Sahel region rainfall over the past 100 years (1910-2009) and 30 years in the future (2050-2080).

\section{Background}

The Sahel is the northern edge of the transition region, south of the desert. In this study the nomenclature Sahel is used is refer to the swath over West Africa located approximately between $10^{\circ} \mathrm{N}$ and $20^{\circ} \mathrm{N}$ it includes much of the countries of Mauritania, Senegal, Mali, Niger, Chad, the Sudan, and the northern fringes of Burkina Faso and Nigeria [4] (Figure 1).

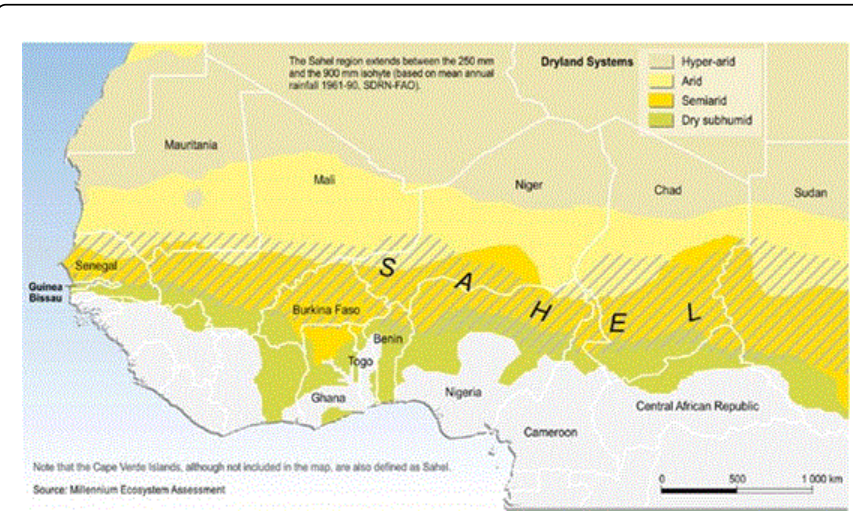

Figure 1: Map showing the geographic location of the Sahel region.

The ecological and geomorphologic diversity is distinctive from other regions in the world. This region is increasingly vulnerable to the impact of climate change; rainfall scarceness, prolonged drought and intensified land use lead to enlarging desertification [3]. The Sahel's climate is confirmed by a dry subtropical climate in the north and a dry tropical climate in the south. This dry trade wind over the Sahel is often named Harmattan [12].

The main climatic feature is the annual cycle of dry and rainy monsoon seasons resulting from the Inter-tropical Discontinuity (ITD) oscillations [13]. The ITD is defined as the interface between the cool, moist south westerly monsoon flow and the warm, dry-laden north easterly Harmattan flow [14]. Drought can be describes by late monsoon onset, it often create severe societal impacts [8]. According to Druyan [8] 95\% of the land use in Sahel West Africa is devoted to agriculture and that $65 \%$ population is employed with agriculture work.

During boreal winter (October-March), northern Sahel region is dominated by the low level north easterly Harmattan winds. The
Harmattan flow is influenced by day to day synoptic scale variability in the strength of the north-south pressure gradient across the region intensifying anti cyclonic conditions notably controlled by ridging of the Libyan high [12]. In boreal summer, atmospheric circulation in the Sahel bound becomes more complex, dominated in a great extent by the West African Monsoon (WAM). The WAM coincides with the crossing of the ITD to its northernmost location.

Desertification from land use change may have contributed to decrease in precipitation in the Sahel region that lead to 1979 and 1980 drought [6].Therefore, changes in future climate is likely to exacerbate the on-going and economic challenges that are already happening in Sahel region because of its dependent on resources that are sensitive in changing climate and combine with additional natural and anthropogenic threats [15].

Xue and Shukla [16] argue that SST anomalies has a strong influence to Sahel drought, both globally and regionals. A prediction was carried out on the regional climate up to 2050 by Paeth and Hense [17]; Wang and Alo [9], to examine the concentration of $\mathrm{CO}_{2}$ and land use change for $\mathrm{A} 1 \mathrm{~B}$ and $\mathrm{B} 1$ emission scenarios it was discover that West Africa climate is dominated by drought.

The key in climate variability in Sahel region is land use change both natural and man-made. Though, the projections of West Africa precipitation changes using atmospheric oceanic general circulation models (AOGCMs) are highly uncertain this is due to inability of climate models to capture the basic characteristics of the present-day climate variability in Sahel region [18].

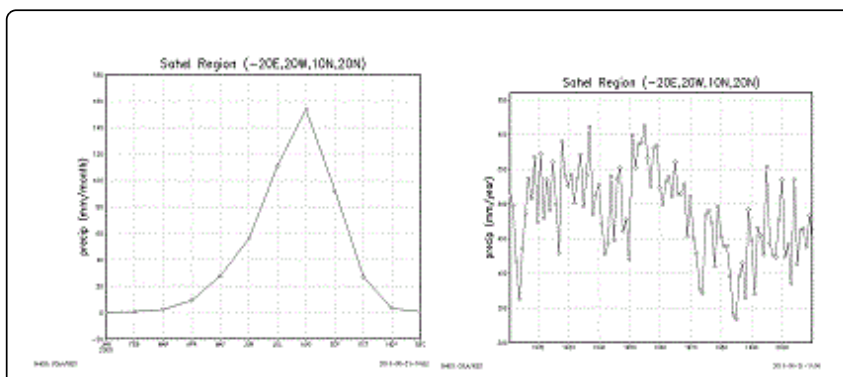

Figure 2: Plot shows annual cycle of precipitation and annual mean precipitation from observational data sets based on 1910-2009 from GPCC for Sahel region.

The Sahel simulated and observes display climatology showing the Sahel region rainfall pattern distribution and the yearly variability in Figure 2 above. The rainy season in Sahel region start around June, July, August and September (JJAS), with the pick at August while the pick of winter season is from November, December, January and February (NDJF).

The region experiences strong variation in climate characterized by the strong seasonality of the climate with a rainy season in the boreal summer and less rain in the winter season. The annual rainfall varies from around $200 \mathrm{~mm}$ in the North of Sahel than $600 \mathrm{~mm}$ in the South [4]. The main feature of climate of Sahel region is WAM system (Figure $3)$. 
Citation: Agumagu O (2016) Observed and Simulated Changes in Precipitation over Sahel Region of West Africa. J Climatol Weather Forecasting 4: 163. doi:10.4172/2332-2594.1000163

Page 3 of 9

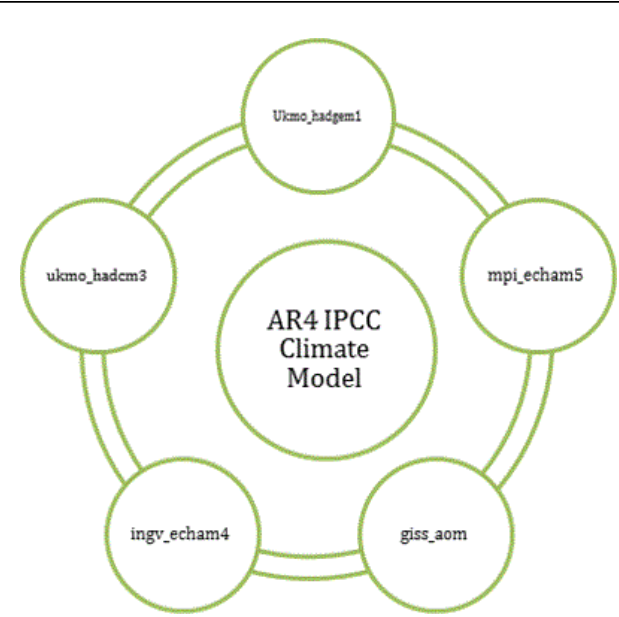

Figure 3: Global climate model used by intergovernmental panel on climate change AR4.

Sahel rainfall is mostly during the movement of the ITCZ. Biasutti [19] and Buontempo [18] argue that the distributions of annual rainfall in Sahel region can be coarsely divided into different similar regions: the highest is along the west coast, the weaker is around Lake Chad and the minimal rainfall distribution is center around Greenwich meridian. The observed feature on inter-annual time scale of Sahel region is dipole structure that associates dry nature in the regions and the wet situations of Guinean coast (south of $10^{\circ} \mathrm{N}$ ) with the presence of warm Gulf of SST anomalies [18,20]. However, the observed dipole is connected to the variability in SST over the Gulf of Guinea that is responsible for dry and wet years in the region [21,22] (Figure 4).
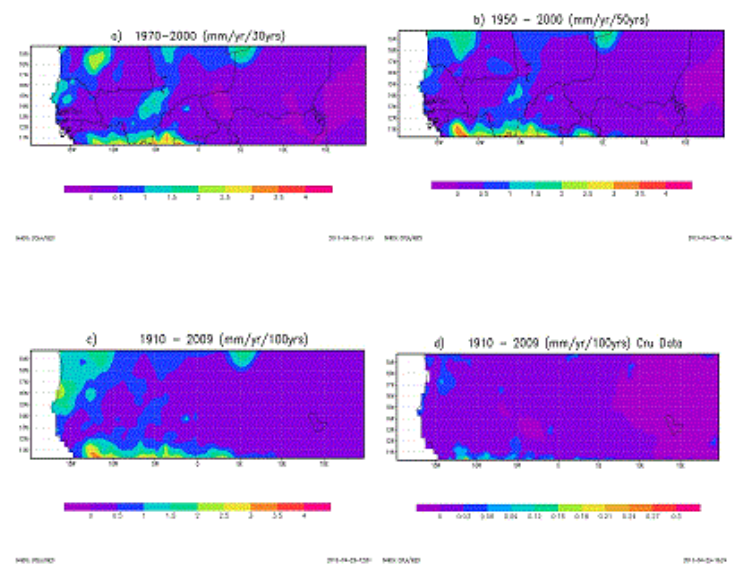

Figure 4: Trends in Yearly Rainfall Anomalies over Sahel Region base (1910-2009) from (GPCC and CRU data) (a) from (1970-2000), (b) (1950-2000), (c) (1910-2009) from GPCC data set while (d) (1910-2009) from CRU data set.

\section{Data and Methods}

Data were obtained from the global monthly precipitation data set held by the GPCC and CRU. Data set from CRU consists of historical time series of monthly precipitation from worldwide [1].

\section{Observation}

The study analyses the precipitation trends over Sahel region using the observe data set supplied from the GPCC, full data Reanalysis product from World Climate Research Programme (WCRP), as historical observation data. The spatial resolution is $0.5^{\circ}$ of Latitude and Longitude [23]. CRU data set was also used to provide the comparison with GPCC data set (Figures 5-7).

The paper analysed the period from 1970 to $2000,1950-2000$ and 1910-2009 for a single time series of area average rainfall over the Sahel region. The rationale behind this period was due to well-documented changes in rainfall climate on a decadal time series in the Sahel region [24]. This region receives about $70 \%$ of the annual rainfall from June to September [25] The long-term variation of the area average yearly anomaly precipitation within this region is shown in Figure 7(c).

The region rainfall climatology is determined mainly by seasonal changes in large-scale circulation, part of which involves the seasonal north-south movement of the ITCZ.

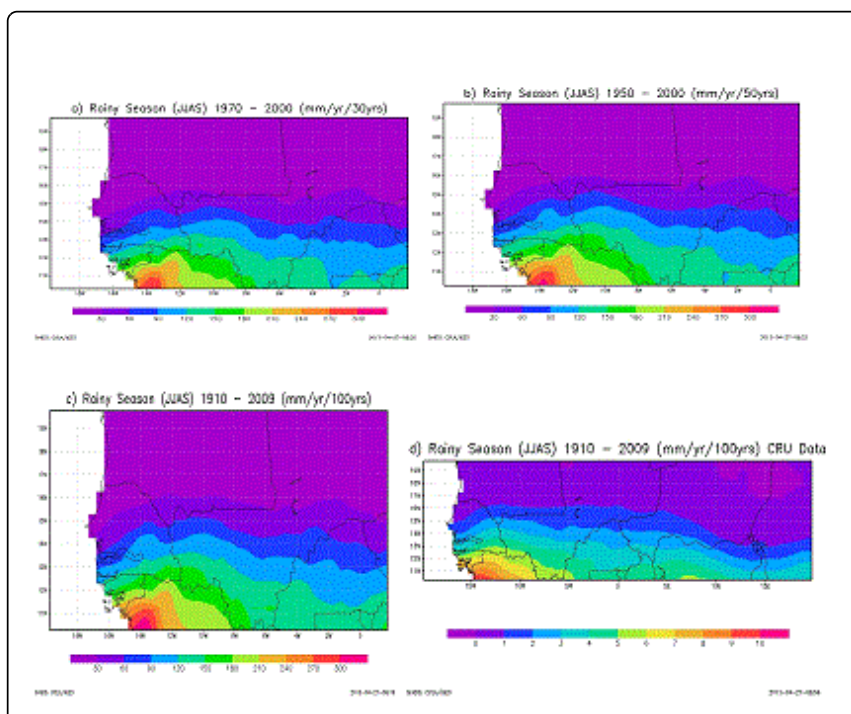

Figure 5: Rainy season JJAS for Sahel region for 100 years, 50 years, and 30 years. Plots are based on GPCC and CRU data. The CRU data is from (d) plot while a, b, and $\mathrm{c}$ are from GPCC data set. 


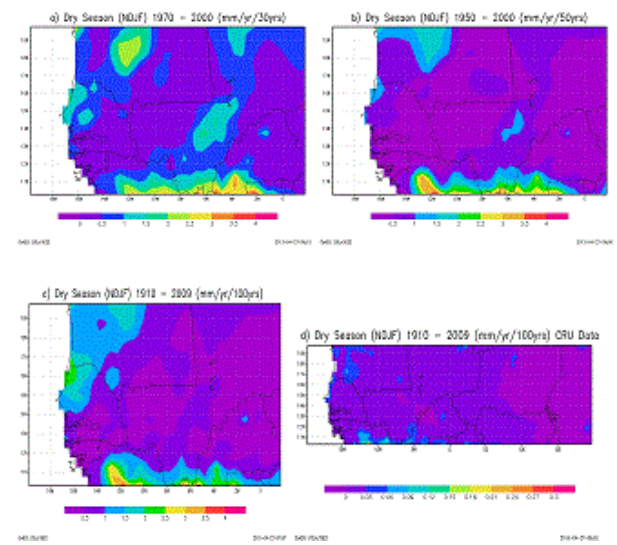

Figure 6: Dry season, NDJF for Sahel region for 100 years, 50 years and 30 years. Plots are based on GPCC and CRU data. The CRU data is plot $\mathrm{d}$ while GPCC data is plot $\mathrm{a}, \mathrm{b}$ and $\mathrm{c}$.

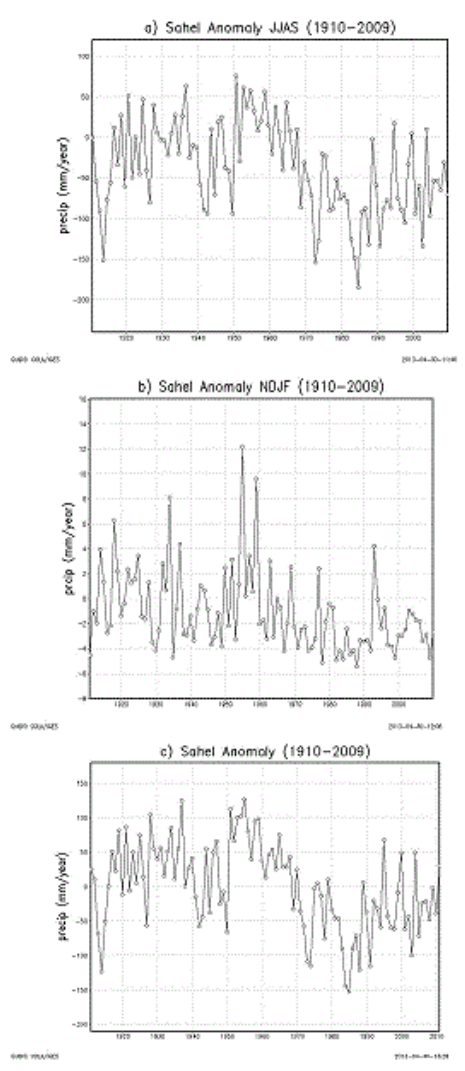

Figure 7: The anomaly of JJAS and NDJF annual average rainfall climatology from 1910-2009 for 100 years, the anomaly plots is based on GPCC data.

\section{Model simulations}

When investigating the effects of one selected forcing mechanism in climatological time series against the background of natural variability, [17] argue that, it is necessary to rely on an ensemble of several model simulations, forced by the same mechanism but starting from different independent initial conditions. GCM used by IPCC AR4 were used to compare seasonal and the annual precipitation variability over Sahel region. The study carried out the analyses using the following AR4 IPCC climate model.

\section{Analyses}

In order to assess precipitation trends over West Africa Sahel region in term of area average, the yearly variability and seasonality for the period of study 1910-2009 the data were analysed using Exceed on Demand and Climate Data Operators (CDO) software. To visualize climate data the result were display in Linux based software, including the Grid Analysis and Display System (GrADS). The analyses were based on GPCC and CRU precipitation data set to observe the spatial distribution of Sahel region. GPCC contribute to the global observing system (GCOS) and the WCRP. The analysis started by extracting the West Africa Sahel region for the study period that is from 1970-2000, 1950-2000 and 1910-2009. These analyses were carried out using CDO command; this was to get the area average over the region.

Again, the study analysed 100 years climatology for the period of 1910-2009, using CRU data set to compare with the GPCC data. The study needed to find out how the data sets are represented in Sahel region precipitation variability. Precipitation in African continent is strongly seasonal; these reflect the leading role of the migrating ITCZ in determining the rainfall season [1]. Thus, the paper analyses the seasonal variability with the pick of rainy season from June to September and the pick of winter season from November to February to get rainfall distribution during JJAS and NDJF Figures 5 and 6 . Again the study analysed the rainfall anomalies; this is to get the anomalies for all the months JJAS and NDJF. The precipitation anomaly time series were represented in Figure 7 . The analyses carried out above were to identify the character and amount of precipitation trends over Sahel West Africa region for 30, 50 and 100 years.

GCMs are reliable to project the future climate change; it has a spatial resolution that is too coarse to accurately model spatially inhomogeneous precipitation [26]. IPCC AR4 models were used in this study to investigate precipitation variability on Sahel region, although the models were used to compare with historical observations and future projection (Figures 8 and 9). The study used, five-member ensemble runs have been conducted corresponding to the above historical observation. The same processes used in observation were also used for model simulation for 20th century. The study used the differences between the wet period JJAS to examine the seasonal and annual variation from the models 20 th century. The models were also run for 21st century to assess the future precipitation trends in Sahel region from the period of $(2050-2080)$ for A1B scenario this was to examine the variability of precipitation trends in future over Sahel and also to compare with the projected precipitation variability over the region. 
Citation: Agumagu O (2016) Observed and Simulated Changes in Precipitation over Sahel Region of West Africa. J Climatol Weather Forecasting 4: 163. doi:10.4172/2332-2594.1000163

Page 5 of 9

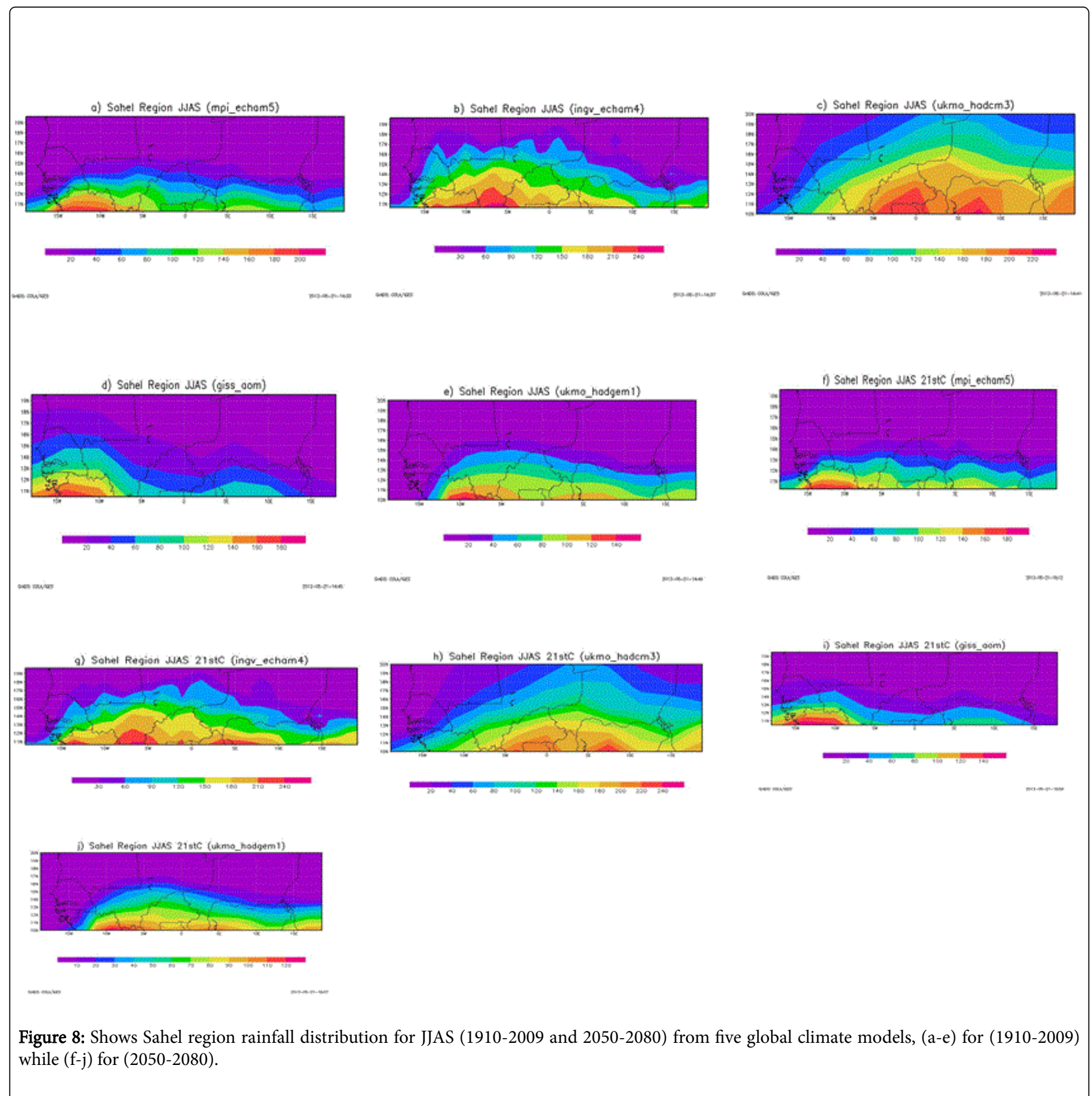



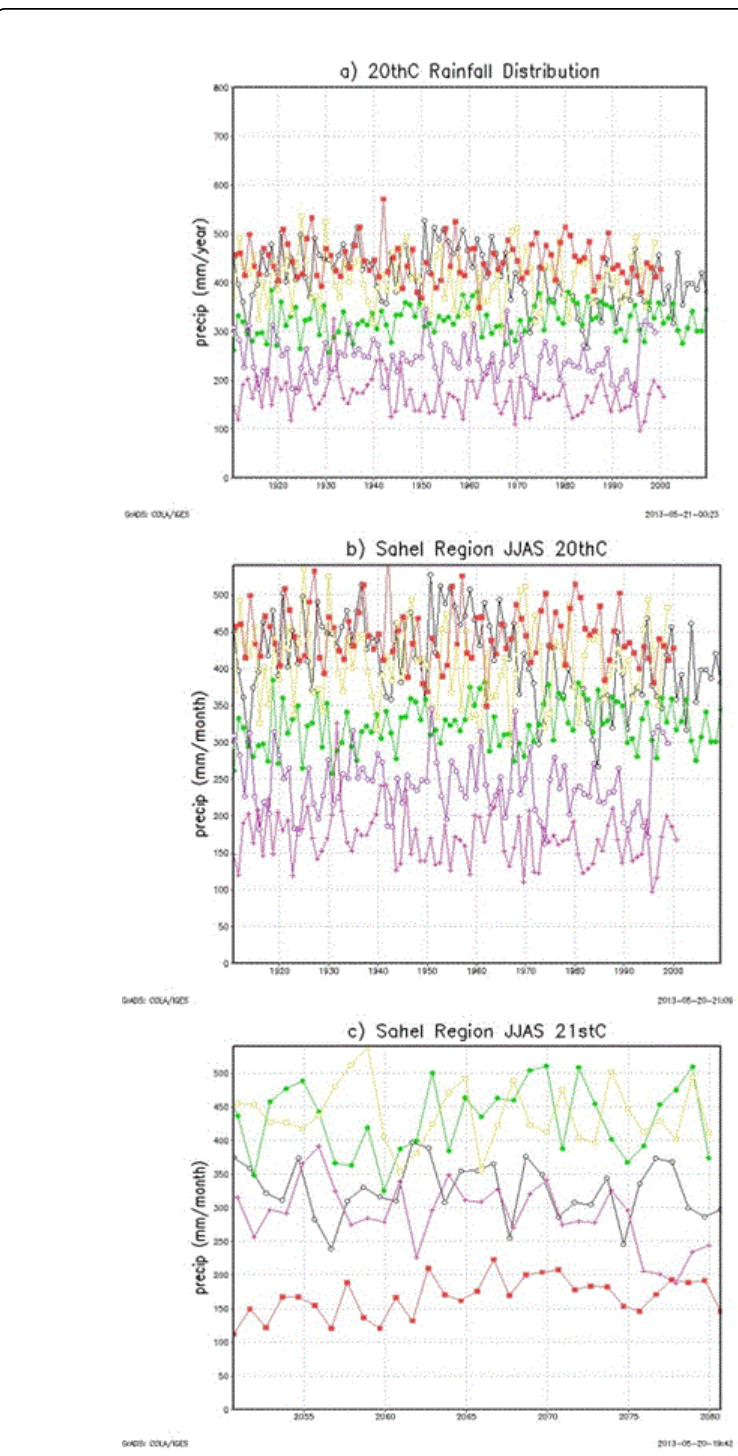

Figure 9: Shows 20th $\mathrm{C}$ and 21st $\mathrm{C}$ model runs. 20th $\mathrm{C}$ for (1910-2009) and 21st C for (2050-2080). Observation climatology is shown in a solid black line in the 20th $\mathrm{C}$ plots. While for the 21 st $\mathrm{C}$ plot the black line indicates the mpi-echam5.

\section{Results}

\section{Mean rainfall pattern}

The result reported in this paper is the analysed precipitation variability of Sahel region in terms of area average rainfall distribution, annual variability and seasonality. The analyses provide a characterization of the weather dynamics of this region. The observed rainfall distributions for the present study 1970-2000, 1950-2000 and 1910-2009. Figure 4, from GPCC and CRU data set, shows that the two data sets has good agreement to locate and observed the pattern of inter-annual variability and the overall trend in Sahel region between the study periods. The observed changes in rainfall indicate that the Sahel may have undergone a climatic change in the first and last half of the twentieth century. The major disagreement is that Sahel rainfalls are not zonally oriented as observed. The study observes high intensity of rainfall over the West coastal and Gulf of Guinea (Figures 4 and 5), such that Hunt [22] noticed in his study.

The observation shows that the Northern part of the Sahel region is characterizes by low precipitation. On the inter annual and decadal time scales, Sahel region rainfall is known to be affected by a variety of regional and global SST difference pattern. The study notices that the region yearly mean rainfall distribution patterns during the past 100 years are not consistent (Figure $7(\mathrm{c})$ ). Though the long-term yearly trends are freely apparent in Sahel region, some changes appear to be reasonably robust and consistent within specific regions. The observed rainfall climatology for the Sahel region in Figure 4 for 30, 50 and 100 year shows that significant inters annual variability is apparent. The decadal length of dry periods occurred between around 1910-1930, 1930-1950 and during 1960-1980s. Figure 7(c), this indicates that an interval of 30 years exist apart from 1960-1980s during Sahel rainfall variability. According to Lebel and Ali [27] the key change of rainfall regime during the droughts period is the dramatically smaller occurrence rate of rain events in June to September, however the monthly average of their point intensity did not change much.

The observed significant variability in Sahel region is characterized by dryness in the second half of 20th $\mathrm{C}$ and the alternating incidence of multi decadal dry and wet influences in recent history; this is associated with the oscillation of lake level [28]. Xue and Shukla [6] argue that desertification in Sahel region may have caused a decrease of precipitation, which led to drought observed in the 1960s. Although number of literature has endeavoured to link the drought to tropical factors such as ENSO, SSTs and ITCZ, yet there is still extensive divergence about the role each of these played in rainfall variability. The drying trend in Sahel region observed in this study is similar with that highlighted by Nicholson and Palo [5]. The analyses observed that the northern Sahel was drying more than the Gulf of Guinea this is because the north Sahel is dominated by the low level north easterly Harmattan winds.

The change in precipitation during 1968 was very abrupt and very extreme. The Sahel latitudes of $\left(15^{\circ} \mathrm{N}\right.$ to $\left.20^{\circ} \mathrm{N}\right)$ mean JJAS rainfall from 1968 to 1997 were roughly lower than the mean for the 30 year period 1931 to 1960 [4]. The drought was more persistence in the central Sahel. Thus the JJAS precipitation climatology from GPCC and CRU data for 1910-2009. Figures 4(c) and 4(d) observed two maxima over west Africa Sahel, one is along West Coast between $5^{\circ} \mathrm{N}$ and $12^{\circ} \mathrm{N}$ and the other is at $10^{\circ} \mathrm{E}$ and $7^{\circ} \mathrm{N}$ over the Eastern Guinea Coast. The North of $15^{\circ} \mathrm{N}$, rainfall rate fall drastically such that $\mathrm{PU}$ and Cook noticed in their study [20].

The study observed that the result display from the two data sets GPCC 100 years (Figure 4(c)) and CRU 100 year's (Figure 4(d)) demonstrates that the variability of rainfall for the data sets does not correspond. The CRU data values are much smaller than GPCC, this show that the observational records for Sahel region are not totally precise. The different trend by GPCC and CRU data set shows that the findings for Sahel region are relatively robust.

The study focus on JJAS rainfall patterns because this four-month accounts for the highest levels of rainfall along the Sahel region Figure 2 above. This four month rainfall patterns determine the intensity or the duration of dry trends that usually occur in the Sahel region. It was observed from the build climatology (Figure 2) that during JJAS the precipitation trends increased. It is deficit in rainfall during JJAS that 
affects seasonal and annual rainfall amount in Sahel region. Although rainy season in Sahel region varies with latitude, fluctuating from about 100 to $200 \mathrm{~mm}$ in the northern extreme to 500 to $600 \mathrm{~mm}$ in the southern Sahel region [4]. The West African Sahel region rainfall is connected to the south-west monsoon movement during the summer; this is because of the specific geometry of the West African continent, which increases the strong sea-land contrasts westwards of about 20 "E [13]. During the boreal summer, the atmospheric circulation in the Sahel region bound becomes more complex, dominated in a great extent by the West African Monsoon (WAM). Peyrille et al. [29] argue that the seasonal cycle of monsoon is linked to the energy balance in the Sahel region.

The study observed from the build climatology the yearly average rainfall over different season in Sahel region. The Four month contributes to $50 \%$ to $60 \%$ of the rainfall in the Sahel region. The northern Sahel rainfall is also relatively high in JJAS. There was a wetting trend observed apparently in the West coastline and in the southern part of the Sahel, i.e., Guinea, southern and southern Burkino Faso (Figure 5). This trend is reflected in the 100 year and with comparable with GPCC and CRU data for JJAS (Figures $5 \mathrm{c}$ and $5 \mathrm{~d}$ ). The overall seasonal rainfall trends observed indicate that the Sahel region rainfall distribution during JJAS assume to be sufficiently not well produced for the purpose of this study.

The observed trends of rainfall distribution during NDJF. Figure 2 above are regarded as boreal winter period in Sahel region. Rainfall distribution during this period is less or no rain. The north Sahel during this period is dominated by the low level north easterly Harmattan winds. The observed rainfall distribution over Sahel region display decreasing in annual rainfall. Figure 6, this is because this season produces minimal or no rainfall in Sahel region. Thus the dry season NDJF plot also shows wetting in the West coastline and in the southern part of the Sahel, i.e., Guinea, southern and southern Burkino Faso area over the 100 year period, but the numbers are very small and so indicate that this wetting trend during the dry season was quite minimal. The study notice that the recent years irregular dry rainy seasons and irregular dry months of JJAS were more recurrent than wet ones in the north of $10^{\circ} \mathrm{N}$ [13] (Figure 6).

\section{Series of annual mean rainfall anomalies}

Anomalies show deviation from the normal either higher or lower. The observed rainfall trends in the Sahel region for JJAS and NDJF annual mean rainfall anomalies for the period of (1910-2009) displayed in Figure 7 were more homogenous. The rainy season JJAS over Sahel is not normally distributed (Figure $7(\mathrm{a})$ ). The basic features of the simulated rainfall changes in the Sahel region are in agreement with observations [22]. The observation shows that the Sahel region is characterizes by drier conditions during the first and second half of 20th century. The droughts that occur during 1984-1985, the JJAS season was anomalously drier than usual due to a large decrease in the trend with an approximate value of $180 \mathrm{~mm}$. This was very dry season, which may coincide with a drought season [30].

Another important features that the paper notice about Sahel drought was, during 1910s and 1940s, the spread about 30 year interval before 1970s drought, this shows that a cycle of 30 year exist in Sahel region drought (Figure 7) [31]. The study notice that the period of 1950 to 1960 s was wet (positive values) (Figure 7). The drought in Sahel region, which is as a result of rainfall deficit, is connected with a general reduction of the occurrence rate of rain events during the period. The noisy spatial features of drought in Sahel region suggest that the seasonal shift in the ITD might not likely be the most contributing mechanism of drought in the region [32], El Nino event might have also play a part in it [21].

\section{Model simulations of climatology}

The sensitivity of the Sahel region rainfall to the changing climate has important significance on the climate models to simulate properly the current mean state of the monsoon system. The simulated patterns of rainfall climatology for Sahel region are display in Figure 8 below. The study uses five global climate models for the 20th C to compare with seasonality from the observational data set. The models were also run for 21st C (2050-2080) to examine the projected scenario over Sahel rainfall variability. The study displays the analyses for each of the five models for the 20th and 21st C for JJAS rainy season (Figure 8). The year-to-year rainfall anomaly of the region is a robust feature across the models simulated, given huge dissimilarities in model formulation, and the difficulties of GCM in simulating tropical rainfall. Although despite the dissimilarities in the model, the models captured the large scales drying of Sahel region during the first and second half of 20th C (Figure 8(a)) [19]. The analyses show slightly similar features to observations across Sahel region. The specific location of anomalies varies from the five-difference model. For example, the decrease in Sahel rainfall during 20th $\mathrm{C}$ is simulated west (east) of $0^{\circ}$ for mpi_echam5.

However, one important feature of the ukmo_hadcm 3 model observed in this study is that the model produces more rainfall Figures $8(\mathrm{c})$ and $8(\mathrm{~h})$ than the other four models. And the ukmo_hadcm3 simulation display shows close trends with the observation. Again ingv_echam 4 also shows more rainfall but not to the extent of ukmo_hadcm3. The simulated rainfall distribution over Sahel appears to be weaker than the observed.

The five models were also used to simulate the 21 st C for A1B scenarios (2050-2080) climatology with mean of the rainy season JJAS showing that southern Sahel region will get wetter (i.e., Burkina Faso, north Ghana, southern Mali, Guinea, northern Nigeria) Druyan [8], but the ukmo_hadcm 3 has a bigger magnitude of increased rainfall (Figure 8). There is a robust drying trend reflected by the five models over Sahel region with reductions being most significant during the past 50 year. The models observe that the southern areas are wetter compared to central Sahara. Thus the five models indicated a drier Sahel in the future, due primarily to increasing greenhouse.

\section{Discussion}

\section{Implication of the result to changes in precipitation}

The changes in precipitation in Sahel region of West Africa in light of the synthesis of the observational data sets evidences as well as the model simulation has shown that Sahel region is characterized by dryness during the first and second half of the 20th C. The simulation shows that Sahel rainfall has changed substantially over the last 100 years in the 20th C. This change has been most notable over Northern part of the region that is describes by low precipitation. The Intensity of rainfall was observed over the West coastline and Gulf of Guinea areas (Figure 4). According to Dennett [10] these differences in Sahel rainfall trends have been reported by Gregory who has studied the spatial variability of dissimilarity between rainfall regimes in Sahel region. 
The climatology in Figure 1 indicates that JJAS is the peak of rainy season while NDJF is the peak of winter season. From the anomalies it can be seen that Sahel rainfall distributions during JJAS were below normal rainfall for the period of 100 years. The time series provided evidence of drought clustering in the region. But the causes of the drought remain uncertain; investigation suggests the existence of a strong correlation between the moisture flux, heat and variations in precipitation within the Sahel [33]. However, despite the models difference in simulating Sahel region the results still indicates drying trends over the region, although Ukmo_hadcm3 indicate a greater magnitude of increase in rainfall. Furthermore, the changes in precipitation trend within GCM influences on the simulation, and the uncertainty due to the model is noticeable.

In general rainfall variability in JJAS is predominantly liable for the tendency for rainfall anomalies of the sign prevail through the analyses. This four-month is responsible for the long down ward trend, the high inter annual persistence of rainfall variation through Sahel region. Therefore, Sahel's region climate in the future is disturbing. It is apparent that Sahel precipitation variability is inextricably tied up to global climate variability, both in the inter-annual and the inter-daedal timescales. Hence, it is likely to say that Sahel's region rainfall responds to El Niño/La Niña events [34].

\section{Conclusion}

The study showed that the change in precipitation over Sahel region is a characterization of the weather dynamics of this region. From the prospective of climate variability based on the scientific evident presented in this paper, it is increasingly observed that Sahel region is characterized by dryness during the first and second half of the 20th C. Rainfall deficit in the region is linked with a general reduction of the incidence rate of rain events during the period. According to Adger et al. [15] climate change is likely to intensify the already felt economic challenges that are experiencing in the region because of the region dependent on rain-fell for its livelihoods.

However, this inescapable climate effect is not a problem of Africa's making, yet Sahel region stand to be predominantly more effected because of their geography, their agricultural dependence, and because of low level of adaptation this region face. It is therefore paramount for policy makers to strategies for facilitating adaptation need to be developed, also ensure investment and promotion of more energy efficient infrastructure in order to cope with these extreme weather and climate events.

\section{Acknowledgement}

The author acknowledges the support by Prof. Martin Todd of University of Sussex United Kingdom during my MSc programme. I am also thankful to National Environmental Standards and Regulations Enforcement Agency (NESREA) for cooperation and assistance from them.

\section{References}

1. Hulme M (1992) Rainfall Changes in Africa: 1931-1960 to 1961-1990. International Journal of Climatology 12: 685-699.

2. Hickler T, Eklundh L, Seaquist J, Smith B, Ardo J, et al. (2005) Precipitation controls Sahel greening trend. Geophysical Research Letters by the American Geophysical Union 32.

3. UNEP and ICRAF (2006) Climate Change and Variability in the Sahel Region, Impacts and Adaptation Strategies in the Agricultural Sector.
4. Nicholson SE (2013) The West African Sahel: A Review of Recent Studies on the Rainfall Regime and Its Inter annual Variability. ISRN Meteorology 2013: 1-32.

5. Nicholson SE and Palo MI (1993) A Re-Revolution of Rainfall Variability in Sahel part1. Characteristics of Rainfall Fluctuation. International Journal of Climatology 13: 371-389.

6. Xue Y, Shukla J (1993) The influence of land surface properties on Sahel climate. Part I: desertification. Journal of Climate 6: 2232-2245.

7. Batterbury S and Warren A (2001) The African Sahel 25 years after the great drought, Assessing progress and moving towards new agendas and approaches. Global Environmental Change 11: 1-8.

8. Druyan LM (2010) Review Studies of 21st century precipitation trends over West Africa. International Journal of Climatology 31: 1415-1424.

9. Wang G, Alo CA (2011) Changes in Precipitation Seasonality in West Africa Predicted by RegCM3 and the Impact of Dynamic Vegetation Feedback. International Journal of Geophysics 2012: 1-10.

10. Dennett MD, Elston J, Rodgers JA (1984) A Reappraisal of Rainfall Trends in the Sahel. Journal of Climatology 5: 353-361.

11. Liebmann B, Blade I, Kiladis GN, Carvalho LMV, Senay GB, et al. (2011) Seasonality of African Precipitation from 1996 to 2009. Journal of Climate 25.

12. Kalu AE (1979) The African dust plume: its characteristics and propagation across West Africa in winter, in Saharan Dust: Mobilization, Transport, Deposition 95-118.

13. Fontaine B, Bigot S (1993) West African Rainfall Deficits and Sea-Surface Temperatures. International Journal of Climatology 13: 271-285.

14. Hayward D and Oguntoyinbo JS (1987) Climatology of West Africa, Rowman and Littlefield.

15. Adger WN, Huq S, Brown K, Conwaya D, Hulme M (2003) Adaptation to climate change in the developing world. Progress in Development Studies 3: 179-195.

16. Xue Y, Shukla J (1998) Model Simulation of the Influence of Global SST Anomalies on Sahel Rainfall 126: 2782-2792.

17. Paeth H, Hense A (2004) SST versus Climate Climatic: Change 65: 179-208.

18. Buontempo C (2010) Sahelian climate: past, current, projections: Sahel and club west Africa Secretariat.

19. Biasutti M (2013) Forced Sahel rainfall trends in the CMIP5 archive. Journal of Geophysical Research 118: 1613-1623.

20. Pu B, Cook KH (2012) Role of the West African Westerly Jet in Sahel Rainfall Variations. Journal of Climate volume 25.

21. Folland CK, Palmer TN, Parker DE (1986) Sahel Rainfall and worldwide, Sea surface temperature 1901-85. Nature 320: 602-607.

22. Hunt BG (2000) Natural climatic variability and Sahelian rainfall trends. Global and Planetary Change 24: 107-131.

23. Munemoto M, Tachibana Y (2010) The recent trend of increasing precipitation in Sahel and the associated inter-hemispheric dipole of global SST. Climate and Ecosystem Dynamics Division 32: 1346-1353.

24. Lucio PS, Molion LCB, Conde FC, Melo MLD (2011) A study on the West Sahel rainfall variability: The role of the inter-tropical convergence zone (ITCZ). African journal of Agricultural Research 7: 2096-2113.

25. Hameed S, Riemer N (2012) Relationship of Sahel Precipitation and Atmospheric Centers of Action. Advances in Meteorology 1-8.

26. Sapiano MRS (2004) Trends and Variability in Observations of Winter Precipitation, A thesis submitted for the degree of Doctor of Philosophy Department of Meteorology.

27. Lebel T, Ali A (2009) Recent trends in the Central and Western Sahel rainfall regime (1990-2007). Journal of Hydrology 375: 52-64.

28. Wang G and Eltahir EAB (2002) Role of vegetation dynamics in enhancing the low-frequency variability of the Sahel rainfall. Water Resources Research 36: 1013-1021.

29. Peyrille P, Lafore JP, Redelsperger JL (2007) An idealized twodimensional framework to study the West African monsoon. Part I: Validation and key controlling factors. Journal of the Atmospheric Sciences 64: 2765-2782. 
Citation: Agumagu O (2016) Observed and Simulated Changes in Precipitation over Sahel Region of West Africa. J Climatol Weather Forecasting 4: 163. doi:10.4172/2332-2594.1000163

Page 9 of 9

30. Reardon T, Matlon P (1989) Seasonal food insecurity and vulnerability in drought-affected regions of Burkina Faso. Seasonal variability in Third World agriculture: The consequences for food security 118-136.

31. Nicholson SE, Enetekhabi D (1986) The Quasi-Periodic Behavior of Rainfall Variability in Africa and Its Relationship to the Southern Oscillation. Arch Met Geoph Biocl Ser A 34: 311-348.

32. Oladipo EO (1993) Some Aspects of the Spatial Characteristics of Drought in Northern Nigeria. Natural Hazards 8: 171-188.
33. Stevenson S, Fox-Kemper BM, Neal R, Deser C, Meehl G (2011) Will there be a significant change to El Nino in the Twenty-First Century. Community Climate System Model CCSM4, 2129-2145.

34. Paulo SL, Luiz CBM, Cati EAV, Fábio CC, Andrea MR, et al. (2012) Dynamical Outlines of the Rainfall Variability and the ITCZ Role over the West Sahel 2: 1-14. 